\title{
Pulp tissue from primary teeth: new source of stem cells
}

\author{
Paloma Dias TELLES ${ }^{1}$, Maria Aparecida de Andrade Moreira MACHADO², Vivien Thiemy SAKAl ${ }^{3}$,
} Jacques Eduardo NÖR ${ }^{4}$

\begin{abstract}
1- DDS, PhD, Assistant Professor, Department of Community Dentistry and Pediatric Dentistry, Dental School, Federal University of Bahia, Salvador, BA, Brazil. 2-DDS, PhD, Professor, Department of Pediatric Dentistry, Orthodontics and Community Health, Bauru School of Dentistry, University of São Paulo, Bauru, SP, Brazil. 3- DDS, PhD, Assistant Professor, Dental School, Federal University of Alfenas, Alfenas, MG, Brazil.

4- DDS, PhD, Professor, Department of Cariology, Restorative Sciences, and Endodontics, School of Dentistry; Department of Biomedical Engineering, College of Engineering, and Department of Otolaryngology, School of Medicine; University of Michigan, Ann Arbor, Michigan, USA.
\end{abstract}

Corresponding address: Profa Dra Paloma Dias Telles - Faculdade de Odontologia da Universidade Federal da Bahia - Departamento de Odontologia Social e Pediátrica - Rua Araujo Pinho, 62, Canela - Salvador, BA - Brazil - 40110-150 - Phone/Fax: +55-71-3283-8975 - e-mail: p-telles@uol.com.br

Received: March 16, 2010 - Modification: May 10, 2010 - Accepted: September 15, 2010

\section{ABSTRACT}

\begin{abstract}
SHED (stem cells from human exfoliated deciduous teeth) represent a population of $\checkmark$ postnatal stem cells capable of extensive proliferation and multipotential differentiation. Primary teeth may be an ideal source of postnatal stem cells to regenerate tooth structures and bone, and possibly to treat neural tissue injury or degenerative diseases. SHED are highly proliferative cells derived from an accessible tissue source, and therefore hold potential for providing enough cells for clinical applications. In this review, we describe the current knowledge about dental pulp stem cells and discuss tissue engineering approaches that use SHED to replace irreversibly inflamed or necrotic pulps with a healthy and functionally competent tissue that is capable of forming new dentin.
\end{abstract}

Key words: Tissue regeneration. Dental pulp. Tissue engineering. Endodontics.

\section{INTRODUCTION}

The history of research on adult stem cells began about 40 years ago. In the sixties, researchers discovered that bone marrow contains at least two kinds of stem cells. One population, called hematopoietic stem cells, forms all the types of blood cells in the body. A second population, called bone marrow stromal cells, was discovered few years later. Stromal cells are a mixed population of progenitor cells that generate bone, cartilage, fat, and fibrous connective tissue $\mathrm{e}^{2,4-7,16,43,45,48,52,57}$. Today, stem cell biology is one of the most fascinating areas of sciences. However, like many other expanding fields of scientific inquiry, research on stem cells raises scientific questions as rapidly as it generates new discoveries.

Postnatal stem cells have been isolated from a variety of tissues including bone marrow, brain, skin, hair follicles, skeletal muscle and dental pulp. These cells are thought to possess great therapeutic potential for repairing damaged and/or defective tissues $^{3-5,8,9,12-15,17,19,20,24,29,35,37,44,58}$. It has been shown that stem cells from human exfoliated deciduous teeth (SHED) represent a population of postnatal stem cells capable of extensive proliferation and multipotential differentiation. The transition from deciduous to permanent teeth is a very unique and dynamic process in which the development and eruption of permanent teeth synchronize with the resorption of the roots of deciduous teeth. Exfoliated deciduous tooth is similar in some ways to an umbilical cord, containing stem cells that may offer a unique postnatal stem cell source for potential clinical applications ${ }^{1,10,39,56}$. It has been demonstrated that stem cells are present within the pulp tissue not only of deciduous teeth, but also in permanent teeth (dental pulp stem cells - DPSC), and in the periodontal ligament (periodontal ligament stem cells - PDLSC) $2,3,7,13,16,19,20,26,28,40,44,51$. This manuscript is designed to serve as a comprehensive synthesis of our current knowledge of stem cells from human exfoliated deciduous teeth and to describe the current efforts on tissue engineering with the use of SHED in order to replace irreversibly inflamed or necrotic pulps due to dental caries by a healthy 
and functionally competent tissue.

\section{Stem cells}

Stem cell is a broad term used to describe a wide variety of cells from varying sources. Stem cells can be divided into two categories - embryonic and adult. Embryonic stem cells are totipotent cells capable of differentiation into virtually any cell type, as well as being propagated indefinitely in an undifferentiated state $^{1,3,5,8,10,14,16-18,24,25,27,28,31-34,38,39,47,49,50,54}$. Adult stem cells are not totipotent, and they can be further classified depending on their origin and differentiation potencial $3,14,19,26,31,35$. The use of embryonic stem cells generates several ethical concerns regarding the consumption of blastocystes. This makes postnatal stem cells a more feasible approach for translation into clinical practice.

Stem cells fascinate us from both theoretical and practical viewpoints. Their defining characteristics - extensive proliferative potential and ability to give rise to one or more differentiated cell types are more common in early mammalian embryos. However, embryonic cells loose these properties as differentiation ensues and growth-promoting signals decline. By adulthood, the few remaining stem cells are dispersed and virtually invisible, but the surviving adult stem cells achieve something remarkable: they can operate as "steady state" - that is, they can generate on average one replacement stem cell and one tissue-specific cell at each division with no apparent limit (Figure 1).

Stem cells differ from other kinds of cells in the body. All stem cells, regardless of their source, have three general properties: they are unspecialized; they are capable of continuous self-renewal; and they can give rise to specialized cell types.

Stem cells are unspecialized. One of the fundamental properties of a stem cell is that it does not have any tissue-specific structures that allow it to perform specialized functions. A stem cell cannot work with its neighbors to pump blood through the body (like a heart muscle cell); it cannot carry molecules of oxygen through the bloodstream (like a nerve cell). However, unspecialized stem cells can give rise to specialized cells, including heart muscle cells, blood cells, or nerve cells $1,7,9,17,24,30$.

Stem cells are capable of self-renewal. Unlike muscle cells, blood cells, or nerve cells, which do not normally replicate themselves, stem cells may replicate many times. A starting population of stem cells that proliferates for several months in the laboratory can yield millions of cells. If the resulting cells continue to be unspecialized, like the parent stem cells, the cells are said to be capable of long-term self-renewal.

Stem cells can give rise to specialized cells. When unspecialized stem cells give rise to specialized cells, the process is called differentiation. The internal signals are controlled by proteins that regulate gene expression and are called transcriptional factors. The external signals for cell differentiation include molecules secreted by other cells, physical contact with neighboring cells, and molecules from the local microenvironment.

\section{Dental caries and pulp response}

Dental caries is the most common chronic disease affecting children in several countries. Despite advances in oral health, dental and oral diseases continue to plague children. Factors contributing to an oral health decline include lack of access to care, inadequate availability of preventive measures and lack of knowledge regarding the importance of oral health. Oral tissue infections and associated nutritional deficits can lead to imbalances in oral flora populations, eventually contributing to compromised overall health and reduced quality of children's life ${ }^{6,7}$. Over the last decades, biomedical research has focused primarily on the understanding of the mechanisms of biological functions in health and disease. For example, our understanding of the mechanisms of dental caries has advanced tremendously ${ }^{5}$. Dentists are faced every day with the task of restoring tooth structure lost during the progression of caries lesions. The development of materials that allow for strong and stable bonding to tooth structure, and the development of esthetic materials that are resistant to wear and degradation in the oral environment, has significantly enhanced the long-term clinical outcomes of restorative procedures. Nevertheless, dental clinicians know that no material available today can mimic all the physical, mechanical and esthetic properties of enamel and dentin ${ }^{5,42}$.

The field of tooth regeneration is one of the ultimate goals of restoring the loss of natural teeth. The ability to obtain and manipulate postnatal tissue easily from individuals to generate biological replacement tooth materials, such as dentin, enamel, and periodontal ligament, or, even better, to replace complete teeth of predetermined size and shape, is extremely valuable $e^{1,8,10}$. Small amounts of reparative dentin can be induced to form in response to subtle tooth injury and cementum also exhibits limited regenerative capabilities. In contrast, enamel exhibits no regenerative capacity because progenitor dental epithelial cells that form enamel loose this ability well before tooth eruption ${ }^{8,9}$. The high susceptibility of teeth to damage, combined with non-regenerative nature of dental tissues, emphasizes the need for regenerative tooth therapies in children and adults $4,10,30,41,55$.

In pathological conditions, such as mild carious dentin lesions, odontoblastic activity is stimulated to produce reactionary dentin. Severe carious lesions or deep cavity preparation may lead to local 


\section{The Promise of Stem Cell Research}

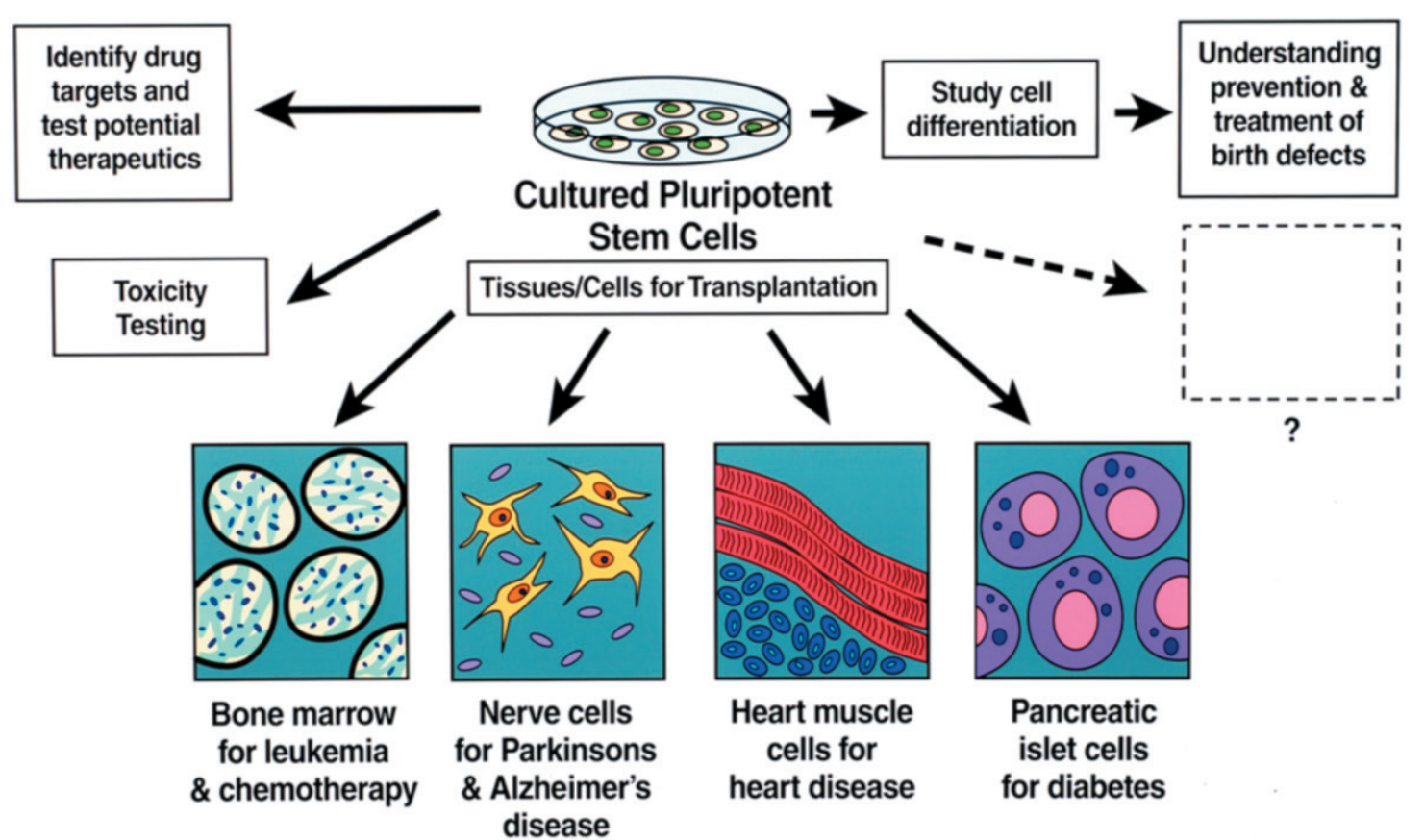

Source: National Institute of Health. The promise of stem cell research [figure on the internet]. Bethesda: NIH; 2009 [cited 2010 May 03]. Available from: http:// alumnimagazine.uconn.edu/sprg2007/feature2.html

Figure 1- Diagram depicting the expected clinical applications of some stem cell research

odontoblastic death. However, undifferentiated cells attracted to the injury site can differentiate into odontoblast-like cells and secrete a reparative dentin matrix. Several lines of evidence suggest the presence of progenitor or postnatal stem cells in the pulp capable of differentiation into odontoblast-like cells and secretion of reparative dentin in vitro ${ }^{11,12}$. Odontoblast cells are post-mitotic and are responsible for the secretion of primary dentin. Indeed, reparative dentin synthesis is a complex biological process. It requires the presence of progenitor cells, their proliferation, migration, recruitment and activation at the injury site to differentiate into odontoblast-like cells secreting the hard protective reparative dentin. The dental pulp is a highly vascularized tissue and pulp cavity preparation results in a subsequent injury to the pulp tissue including the blood vessels. It is recognized that injured endothelial cells release chemotactic factors and signaling molecules to initiate the inflammatory process and express adhesion molecules necessary for the recruitment of inflammatory and progenitor cells for initiating the healing process ${ }^{14,15}$. The presence of inflammation, which will be exacerbated by bacterial infection, is well recognized as a moderator of regeneration and will probably inhibit regenerative processes as long as it is maintained ${ }^{16,18}$.

The concept of migration of stem cells to the site of injury for differentiation into a new generation of odontoblast-like cells is very important event for cell recruitment during regeneration when the vitality of the primary odontoblasts is compromised $17,19,20$. It is unclear whether this reflects a direct effect on the stem cells for regeneration or the molecular signaling processes responsible for their differentiation. Nevertheless, the presence of inflammation will compromise stem cell recruitment and differentiation during regeneration 22,23 . An understanding that local angiogenesis is a physiologic event during healing at all wound sites, including the dental pulp with a remarkable importance of nutrition during the healing process, and it may also increase the opportunities for perivascular stem cells recruitment during regeneration ${ }^{26}$.

Dental pulp-derived cells are potentially a useful alternative for cell replacement in the treatment of tissues known to contain neural stem cells. It has been demonstrated the first successful induction of neural differentiation of rat dental pulp-derived cells, particularly into a glial cell lineage. Successful in vitro and in vivo differentiation of neural stem cells obtained from bone marrow into neurons and/ or oligodendrocytes has been also reported $38,39,48$. The authors concluded that the existence of neural stem cells in tissues other than the central nervous system may represent a significant step toward providing more diverse and multiple sources of stem cells for regenerative medicine ${ }^{38}$.

The understanding of pulp biology has improved significantly in recent years. However, it is still 
not possible to state with certainty which cell populations and which specific molecular signaling pathways predominate during dental regeneration. If pulpal stem cells are to be optimally harnessed for dental regeneration, then strategies are required to ensure their effective recruitment at sites of injury. Whilst such recruitment does occur during natural regeneration, it is a somewhat haphazard process lacking in control. Directed recruitment of these cells might be achieved through local application of enriched cell populations, either by harvesting cells from non-autologous teeth or autologous shed deciduous primary teeth.

\section{Dental pulp tissue engineering with the use of SHED}

Although conventional restorative materials, such as amalgam, composite resin and glass ionomer cement, have been proven effective in the maintenance of teeth in the oral cavity, they clearly present a limited lifespan, thus requiring replacement over time. Additionally, a significant percentage of treated teeth undergo pulp inflammation and necrosis, requiring further endodontic treatment and prosthetic reconstruction or tooth extraction. Therefore, the development of new techniques capable of regenerating lost tooth structure would benefit the population significantly ${ }^{13}$.

Nowadays, tissue engineering, which corresponds to a multidisciplinary science that brings together biology, engineering and clinical sciences with developing new tissues and organs ${ }^{42}$, constitutes a promise as a new method to repair congenital and/ or diseased teeth ${ }^{36,57}$. Particularly, the main goal of dental pulp tissue engineering is to replace the inflamed or necrotic pulp by a healthy and functional tissue, capable of forming new dentin. This science is based on principles in which undifferentiated cells placed into biocompatible scaffolds respond to specific signals that induce their proliferation, migration and differentiation into specialized cell lineages.

Common tissue engineering involves the seeding of appropriate cells in biodegradable scaffolds built with desirable mechanical features and the stimulation of cell growth and differentiation in vitro. When this set is implanted in vivo, it may undergo remodeling and maturation into a complete functional tissue ${ }^{36,57}$. Therefore, dental pulp tissue engineering may be the first step toward dentin regeneration in necrotic teeth, as well as an alternative to conventional endodontic treatment ${ }^{21}$, with the advantage of restoring tooth vitality. Hence, the identification of appropriate cells, the development of conductive scaffolds and the understanding of morphogenetic signaling required to induce cells to regenerate lost tissues are mandatory $42,43,53,59$.

Stem cells can be induced to differentiate into a specific phenotype through the manipulation of cell culture conditions. It is possible to control or restrict available differentiation pathways and selectively generate enriched cultures with a particular phenotype. These manipulations include cell stimuli with specific cytokines, growth factors, amino acids, other proteins and active ions, and co-culture with a specific cell type or tissue ${ }^{46}$.

In vivo evidence for pulp cells being capable of generating a dentin-pulp-like complex have been demonstrated by Gronthos, et al. ${ }^{18}$ (2000) and Miura, et al. ${ }^{39}$ (2003) who transplanted DPSC and SHED, respectively, mixed with hydroxyapatite/ tricalcium phosphate into immunocompromised mice. Within 6 weeks, a dentin-like structure lined with odontoblast-like cells that surrounded a pulp-like interstitial tissue and had their process penetrating into tubular structures was observed. Moreover, collagen fibers oriented perpendicularly to the odontoblast layer within the dentin, which is characteristic of primary dentin. Dentin-like material formed in the implants had a mineralized globular aspect, compatible with human dentin structure. In addition, odontoblast-like cells and the remaining pulp cells were from the donor ${ }^{18,39}$. When DPSC were seeded onto human dentin surface and implanted into immunocompromised mice, scattered reparative dentin-like structure was deposited on the dentin surface ${ }^{4}$.

Cordeiro, et al. ${ }^{11}$ (2008) evaluated morphologic characteristics of the tissue formed when SHED seeded in biodegradable scaffolds prepared within human tooth slices were transplanted into immunodeficient mice. The resulting tissue presented architecture and cellularity that closely resemble those of a physiologic dental pulp. Ultrastructural analysis with transmission electron microscopy and immunohistochemistry for dentin sialoprotein suggested that SHED differentiated into odontoblast-like cells in vivo. Notably, SHED also differentiated into endothelial-like cells, as demonstrated by B-galactosidase staining of cells lining the walls of blood-containing vessels in tissues engineered with SHED stably transduced with LacZ.

Using the same experimental model, Sakai, et al. ${ }^{48}$ (2010) tested the hypothesis that SHED differentiate into functional odontoblasts and endothelial cells. SHED differentiated into functional odontoblasts that generated new dentin, as determined by tetracycline staining and confocal microscopy. These cells also differentiated into vascular endothelial cells, as determined by B-galactosidase staining of LacZ-tagged SHED. In vitro, vascular endothelial growth factor (VEGF) induced SHED to express VEGFR2, CD31, and VECadherin (markers of endothelium) and organize 
into capillary-like sprouts. VEGF induced ERK and AKT phosphorylation (indicative of differentiation), while inhibiting phosphorylation of STAT3 (indicative of stemness).

We are at an exciting point of a new era of restorative dentistry harnessing the biological activity of the dental tissues to facilitate wound healing and tissue regeneration. There is still much to learn of the nature, potentiality and behavior of dental stem cells, but the opportunities for their exploitation in dental tissue regeneration are immense and will lead to significant benefits for the management of the effects of dental disease ${ }^{44}$.

\section{REFERENCES}

1- Arora V, Arora P, Munshi AK. Banking stem cells from human exfoliated deciduous teeth (SHED): saving for the future. J Clin Pediatr Dent. 2009;33:289-94.

2- Baba O, Qin C, Brunn J, Jones J, Wygant J, McIntyre B, et al. Detection of dentin sialoprotein in rat periodontium. Eur J Oral Sci. 2004;112:163-70.

3- Ballini A, De Frenza G, Cantore S, Papa F, Grano M, Mastrangelo $\mathrm{F}$, et al. In vitro stem cell cultures from human dental pulp and periodontal ligament: new prospects in dentistry. Int J Immunopathol Pharmacol. 2007;20:9-16.

4- Batouli S, Miura M, Brahim J, Tsutsui TW, Fisher LW, Gronthos $\mathrm{S}$, et al. Comparison of stem-cell-mediated osteogenesis and dentinigenesis. J Dent Res. 2003;82:976-81.

5- Casagrande L, Mattuela LG, Araújo F, Eduardo J. Stem cells in dental practice: perspectives in conservative pulp therapies. J Clin Pediatr Dent. 2006;31:25-7.

6- Chai $Y$, Jiang $X$, Ito $Y$, Bringas $P$ Jr, Han J, Rowitch DH, et al. Fate of the mammalian cranial neural crest during tooth and mandibular morphogenesis. Development. 2000;127:1671-9.

7- Chai Y, Slavkin HC. Prospects for tooth regeneration in the 21st century: a perspective. Microsc Res Tech. 2003;60:46-79.

8- Chang J, Zhang C, Tani-Ishii N, Shi S, Wang C. NF-kappaB activation in human dental pulp stem cells by TNF and LPS. J Dent Res. 2005;84:994-8.

9- Chute JP, Muramoto GG, Whitesides J, Colvin M, Safi R, Chao NJ, et al. Inhibition of aldehyde dehydrogenase and retinoid signaling induces the expansion of human hematopoietic stem cells. Proc Natl Acad Sci USA. 2006;103:11707-12.

10- Coppe C, Zhang Y, Den Besten PK. Characterization of primary dental pulp cells in vitro. Pediatr Dent. 2009;319: 467-71.

11- Cordeiro MM, Dong Z, Kaneko T, Zhang Z, Miyazawa M, Shi S, et al. Dental pulp tissue engineering with stem cells from exfoliated deciduous teeth. J Endod. 2008;34:962-9.

12- Dobie K, Smith G, Sloan AJ, Smith AJ. Effects of alginate hydrogels and TGF-B1 on human dental pulp repair in vitro. Connect Tissue Res. 2002;43:387-90.

13- Dualibi MT, Dualibi SE, Young CS, Bartlett JD, Vanacti JP, Yelick PC. Bioengineered teeth from cultured rat tooth bud cells. J Dent Res. 2004;83:523-8.

14- Edwards PC, Mason JM. Gene-enhanced tissue engineering for dental hard tissue regeneration: (2) dentin-pulp and periodontal regeneration. Head Face Med. 2006;2:16.

15- Friedlander LT, Cullinam MP, Love RM. Dental stem cells and their potential role in apexogenesis and apexification. Int Endod J. 2009;42:955-62.

16- Goldberg M, Lacerda-Pinheiro S, Jegat N, Six N, Septier D, Priam $F$, et al. The impact of bioactive molecules to stimulate tooth repair and regeneration as part of restorative dentistry. Dent Clin North Am. 2006;50:277-98.
17- Gronthos S, Brahim J, Li W, Fisher LW, Cherman N, Boyde A. Stem cells properties of human dental pulp cells. J Dent Res. 2002;81:531-5.

18- Gronthos S, Mankani M, Brahim J, Robey PG, Shi S. Postnatal human dental pulp stem cells (DPSCs) in vitro and in vivo. Proc Natl Acad Sci USA. 2000;97:13625-30.

19- Gronthos S, Zannettino A, Hay SJ, Shi S, Graves SE, Kortesidis $A$, et al. Molecular and cellular characterization of highly purified stromal stem cells derived from human bone marrow. J Cell Sci. 2003; 116:1827-35.

20- Hargreaves KM, Giesler T, Henry M, Wang Y. Regeneration potential of the young permanent tooth: what does the future hold? J Endod. 2008;34:S51-6.

21- Harumi Miyagi SP, Kerkis I, Costa Maranduba CM, Gomes CM, Martins MD, Marques MM. Expression of extracellular matrix proteins in human dental pulp stem cells depends on the donor tooth conditions. J Endod. 2010;36:826-31.

22- Hu B, Nadiri A, Kuchler-Bopp S, Perrin-Schimitt F, Peters H, Lesot $H$. Tissue engineering of tooth crown, root and periodontium. Tissue Eng. 2006:12:2069-75.

23- Huang FM, Tsai CH, Chen YJ, Liu CM, Chou MY, Chang Y-C. Upregulation of tissue-type plasminogen activator in inflamed human dental pulps. Int Endod J. 2005;38:328-33.

24- Huang GT. Pulp and dentin tissue engineering and regeneration: current progress. Regen Med. 2009;4:697-707.

25- Huang GT, Gronthos S, Shi S. Mesenchymal stem cells derived from dental tissues vs. those from other sources: their biology and role in regenerative medicine. J Dent Res. 2009;88:792-806. 26- Huang GT, Shagramanova K, Chan S. Formation of odontoblastlike cells from cultured human dental pulp cells on dentin in vitro. J Endod. 2006;32:1066-73.

27- Iohara K, Nakashima M, Ito M, Ishikawa M, Nakashima A, Akamine A. Dentin regereration by dental pulp stem cell therapy with recombinant human bone morphogenetic protein 2. J Dent Res. 2004;83:590-5.

28- Iohara K, Zheng L, Wake H, Ito M, Nabekura J, Wakita H, et al. A novel stem cell source for vasculogenesis in ischemia: subfraction of side population cells from dental pulp. Stem Cells. 2008;26:2408-18.

29- Ivanovski S, Gronthos S, Shi S, Bartold PM. Stem cells in the periodontal ligament. Oral Dis. 2006;12:358-63.

30- Kaigler D, Krebsbach PH, Wang Z, West ER, Harger K, Mooney DJ. Transplanted endothelial cells enhance orthotopic bone regeneration. J Dent Res. 2006;85:633-7.

31- Koyama N, Okubo Y, Nakao K, Bessho K. Evaluation of pluripotency in human dental pulp cells. J Oral Maxillofac. Surg. 2009;67:501-6.

32- Leonardi R, Loreto C, Caltabiano R, Calatabiano C. Immunolocalization of CD44s in human teeth. Acta Histochem. 2006;108:425-9.

33- Liu H, Li W, Shi S, Habelitz S, Gao C, Denbesten P. MEPE is downregulated as dental pulp stem cells differentiate. Arch Oral Biol. 2005; 50:923-8.

34- Mao JJ, Giannobile WV, Helms JA, Hollister SJ, Krebsbach PH, Longaker MT, et al. Craniofacial tissue engineering by stem cells. J Dent Res. 2006;85: 966-79.

35- Maria OM, Khosravi R, Mezey E, Tran SD. Cells from bone marrow that evolve into oral tissues and their clinical applications. Oral Dis. 2006,13:11-6.

36- Mathieu S, Battari A, Dejou J, About I. Role of injuried endothelial cells in the recruitment of human pulp cells. Arch Oral Biol. 2005; 50:109-13.

37- Melero-Martin JM, Zhan ZA, Picard A, Wu X, Paruchuri S, Bischoff J. In vivo vasculogenic potential of human blood-derived endothelial progenitor cells. Blood. 2007;109:4761-8.

38- Miura M, Chen XD, Allen MR, Bi Y, Gronthos S, Seo BM, et al. Crucial role of caspase-3 in osteogenic differentiation of bone marrow stromal stem cells. J Clin Invest. 2004;114:1704-13. 
39- Miura M, Gronthos S, Zhao M, Lu B, Fisher LW, Robey PG, et al. SHED: stem cells from human exfoliated deciduous teeth. Proc Natl Acad Sci USA. 2003;100:5807-12.

40- Miura M, Miura Y, Sonoyama W, Yamaza T, Gronthos S, Shi S. Bone marrow-derived mesenchymal stem cells for regenerative medicine in craniofacial region. Oral Dis. 2006;12:514-22.

41- Modino A, Sharpe P. Tissue engineering of teeth using adult stem cells. Arch Oral Biol. 2005;50:255-8.

42- Morsczeck C, Frerich B, Driemel O. Dental stem cell patents. Recent Pat DNA Gene Seq. 2009;3:39-43

43- Morsczeck C, Schmalz G, Reichert TE, Völlner F, Galler K, Driemer $\mathrm{O}$. Somatic stem cells for regenerative dentistry. Clin Oral Investig. 2008;12:113-8.

44- Nakashima M, Akamine A. The application of tissue engineering to regeneration of pulp and dentin in endodontics. J Endod. 2005;31:711-7.

45- Nör JE. Tooth regeneration in operative dentistry. Oper Dent. 2006:31:633-42.

46- Pierdomenico L, Bonsi L, Calvitti M, Rondelli D, Arpinati M, Chirumbolo $G$, et al. Multipotent mesenchyml stem cells with immunosuppressive activity can be easily isolated from dental pulp. Transplantation. 2005;80:836-42.

47- Prince ME, Sivanandan R, Kaczorowski A, Wolf GT, Kaplan MJ, Dalerba $P$, et al. Identification of a subpopulation of cells with cancer stem cell properties in head and neck squamous cell carcinoma. Proc Natl Acad Sci USA. 2007;104:973-8.

48- Sakai VT, Zhang Z, Dong Z, Neiva KG, Machado MAAM, Shi $S$, et al. SHED differentiate into functional odontoblasts and endothelium. J Dent Res. 2010;89:791-6.
49- Shi S, Bartold PM, Miura M, Seo BM, Robey PG, Gronthos S. The efficacy of mesenchymal stem cells to regenerate and repair dental structures. Orthod Craniofac Res. 2005;8:191-9.

50- Sloan AJ, Smith AJ. Stem cells and dental pulp: potencial roles in dentine regeneration and repair. Oral Dis. 2007;13:151-7. 51-Sloan AJ, Waddington RJ. Dental pulp stem cells: what, where, how? Int J Paediatr Dent. 19:61-70.

52- Smith AJ, Patel M, Graham L, Sloan AJ, Cooper PR. Dentine regeneration: the role of stem cells and molecular signaling. Oral Biosci Med. 2005;2:127-32.

53- Spradling A, Drummond-Barbosa D, Kai T. Stem cells find their niche. Nature. 2001;414:98-104

54- Stokowski A, Shi S, Sun T, Bartold PM, Koblar SA, Gronthos S. EphB/ephrin-B interaction mediates adult stem cell attachment, spreading, and migration: implications for tissue repair. Stem Cells. 2007; 25:156-64.

55- Thesleff I, Sharpe P. Signalling networks regulating dental development. Mech Dev. 2005;67:111-23.

56- Tran-Hung L, Mathieu S, About I. Role of human pulp fibroblasts in angiogenesis. J Dent Res. 2006:85:819-23.

57- Tziafas D. The future role of molecular approach to pulpdentinal regeneration. Caries Res. 2004;38:314-320.

58- Weissman IL. Stem cells: units of development, units of regeneration, and units in evolution. Cell. 2000;100:157-68.

59- Yu JH, Shi JN, Deng ZH, Zhuang H, Nie, X, Wang R, et al. Cell pellets from dental papillae can reexhibit dental morphogenesis and dentinogenesis. Biochem Biophys Res Commun. 2006;346:11624. 